\title{
Governance of Urban Sustainability Transitions
}

My research group is involved in collaborations with the dynamic 'Amsterdam Metropolitan Region (MRA)' and 'Rotterdam-The Hague Metropolitan Region (MRDH)', with the objective to investigate the complex governance challenges and opportunities related to urban sustainability transitions, mainly through transdisciplinary collaboration. The resulting knowledge and skills are used to support and engage with Transformative Social-Ecological Innovation (TSEI) in-the-making, which in turn will generate new knowledge and skills (i.e. in iterative learning cycles). This chapter starts with a brief overview of urban sustainability challenges (Sect. 7.1). Research activities are centred around the transition to climate-resilient and healthy cities (Sect. 7.2), feeding and greening megacities (Sect. 7.3), as well as the transition from linear to circular and regenerative economies and cultures in (mega) cities (Sect. 7.4). In parallel, a new transdisciplinary Minor is developed, called 'Collaboration for the City of the Future' (Sect. 7.4).

\subsection{Urban Challenges and Developments}

Sustainable Development Goal 11 (SDG 11), in particular, is dedicated to making cities inclusive, safe, sustainable, and resilient, as part of the UN Agenda for 2030, while cities play a central role in reaching many of the other SDGs. However, the cities of the twenty-first century are facing enormous challenges in reaching the required level of sustainability and improving the living standard of citizens. More and more people are living together in an increasingly compact space. They are looking for a better life, employment, better education, better healthcare, better infrastructure, and social services.

Urban population is expected to grow with 1.5 billion in the next 15 years, and 3 billion by 2050 (cf. United Nations, World Urbanization Prospects 2018). 'Cities today occupy approximately $4 \%$ of the total land, but contribute $70 \%$ of global (GDP), over $60 \%$ of global energy consumption, $70 \%$ of greenhouse gas emissions, and $70 \%$ of global waste' (ibid.). How the world meets the challenge of sustainable 
development, in particular for reaching many of the Sustainable Development Goals (SDGs), will be intimately tied to the process of urbanization and the governance of urban sustainability transitions. Hence, cities need to be organized more efficiently and sustainably with regard to the supply of food, raw materials, and energy, as well as finding ways of adapting cities to climate change, keep the cities attractive and healthy, and to address poverty and inequalities (see below overview of urban challenges).

While urbanization poses serious challenges, cities are also breeding grounds for innovation and can be powerhouses for sustainable development, if the right policies are put in place. 'Cities provide a wealth of opportunities, jobs included, and generate over $80 \%$ of gross national product across the globe' (cf. UNFPA 2019). Nowhere in human culture is the centrality of collaboration and sharing more obvious than in the city' (cf. Agyeman and McLaren 2017). The city is not just a venue for sharing, but is historically a shared entity in itself: the result of shared co-production (ibid.). For many cities, though, the pace of urbanization is overwhelming both national and local capacities to capitalize on the opportunities before them (C40 2018). 'The problems are multi-sectoral, the available data is incomplete, and there is a lot of disagreement over how to proceed. The most common challenges include unplanned urban expansion, ineffectual governance and legal frameworks, and a dearth of local-level revenue generation mechanisms' (cf. C40 2018). 'Cities with the greatest infrastructure needs often lack the capacity and knowledge to develop bankable projects. This is exacerbated by limited access to credit and an insufficient ability to take advantage of endogenous sources of finance, which, for example, could be used to invest in core infrastructure such as water, drainage, and energy' (ibid.).

Within this context, several important urban sustainability challenges can be identified (in no particular order):

- Population growth: Projections are that the world population will grow from 7.8 billion in 2020 to 9 billion in 2037 (World Population Prospects: The 2019 Revision). Approximately $55 \%$ of the world's population lives in urban areas, a proportion that is expected to increase to $68 \%$ by 2050 (ibid.). Projections are that by 2030 there will be 41 megacities, defined as urban agglomerations of more than ten million people (United Nations 2018). 'While population is expected to continue growing exponentially across most of the globe, this is less so in Europe. While many challenges still faced are related to population pressure, Europe also has to cope with new challenges related to a declining and ageing population in many cities' (cf. JRC 2019).

- Climate change: Cities account for more than $70 \%$ of global energy use and related $\mathrm{CO}_{2}$ emissions, and thus play a key role in climate change mitigation (IPCC 2014; UN Department of Economic and Social Affairs Population Division 2015; Hopkins et al. 2016). Examples of climate mitigation can be found in the ongoing urban energy transition (e.g. solar panels, recycling and waste management, high-performance insulation, etc.), and in transportation (e.g. electric vehicle fleets for cities, autonomous vehicles, microtransit, green 
spaces for improving air quality, mitigation of the urban heat island effect, etc.). At the same time, cities are vulnerable for the impacts of climate change, with increased risk of heat-related deaths, extreme weather events, food and resource shortages, power outages, and infrastructure failures. 'Over $90 \%$ of all urban areas are coastal, putting most cities on Earth at risk of flooding from rising sea levels and powerful storms' (cf. The Global Risks Report 2020; World Economic Forum 2020). One of the major challenges for the governance of future cities is the combination of climate change and the local urban heat island effect (Mohajerani et al. 2017; UN-Habitat 2020). Hence, climate change adaptation is necessary for creating more resilient and healthy cities, for example, by means of green-blue infrastructure (see Sect. 7.2).

- Feeding megacities: 'Urbanization will drive intensified consumer demand and value chain concentration, while the distance between food producers and food consumers will continue to widen' (cf. NewForesight and Commonland 2017). For more details, see Sect. 7.3.

- Mobility: 'Environmental pollution, congestion, and long commuting times are just some of the issues related to mobility in cities. A decrease in ownership of private vehicles in favour of efficient and connected public transport and active mobility modes could greatly ease these problems' (cf. JRC 2019).

- Affordable housing: 'The recent scale-up of foreign and corporate investments in residential urban property has transformed patterns of ownership. Prices are recovering faster than earnings, and the availability of housing is low. Short-term rental platforms may also cause property prices to spiral and negatively affect local liveability' (cf. JRC 2019).

- Poverty and inequalities: 'Cities are home to high concentrations of poverty. Nowhere is the rise of inequality clearer than in urban areas, where wealthy communities coexist alongside, and separate from, slums and informal settlements' (cf. UNFPA 2019). 'Many people are also likely to be pushed into poverty due to higher prices of essential commodities in urban areas' (cf. WHO 2016). In addition, more enduring patterns of inequality need to be taken into account (Tilly 1998; Tonkiss 2017). Some of the deepest and most persistent patterns do not only derive from economic factors, but are generated around social distinctions which legitimize the unequal distribution of resources and opportunities between different groups across different contexts (Tilly 1998; Tonkiss 2017), which in turn could result in economic differences. Therborn and Aboim (2014) conceptualized multiple forms of inequality: (1) vital inequality (differential health outcomes, mortality rates, life expectancies, distributions of hunger and malnutrition, exposure to environmental and other types of somatic risk), (2) resource inequality (access to and command over economic and non-economic resources, goods, or capitals), and (3) existential inequality (disparities of dignity, autonomy, freedom, opportunity, and self-determination). From a sociological perspective these kinds of inequalities are treated as a relational problem, in terms of dynamic social relations between individual and groups (Tonkiss 2017). 
- Urban health: The types of urban health challenges are varied. Non-communicable diseases (NCDs) - the diseases that result from a combination of our biology, how we live our lives, and the environment we live in-are endemic to city life (WHO 2016). A study of more than 100 countries found that body mass index (BMI) and blood cholesterol levels, both major risk factors for NCDs, rose rapidly with increases in national income and level of urbanization (Ezzati et al. 2005). WHO estimates that $68 \%$ of global deaths were caused by NCDs in 2012 (16). Much of this burden will be concentrated in cities. In addition, urban environments offer favourable grounds for the spread of infectious diseases, especially in areas of high population densities with low resources such as slums. Increased international travel and migration have resulted in cities becoming important hubs for the transmission of infectious diseases, as shown by recent pandemics such as H1N1, Ebola virus, and Corona-virus (COVID-19). Other urban health concerns include air pollution and mental health issues, while the concentration of poverty in overcrowded urban areas also constitutes an increased risk for violence and injuries (WHO 2016). Emerging trends, such as ageing, and the prevalence of malnutrition and obesity and mental health in cities have to be tackled with a long-term effort (JRC 2019).

- Environmental footprint: 'Providing water, energy, and food security for urban populations results in significant environmental pressure beyond city boundaries. Four of nine planetary boundaries have already been exceeded due to human activities. Several lifestyle and behavioural changes can help city inhabitants significantly reduce their environmental footprint, such as shifting to a healthy diet, reducing waste, using active or public mobility modes, or choosing sustainable energy sources' (cf. JRC 2019).

In short, cities are facing enormous development challenges, such as climate change adaptation, the energy transition (i.e. climate change mitigation), circularization, preservation of biodiversity, improving quality of life, addressing poverty and inequalities, and maintaining and improving public health (Gallopín 2006; Gill et al. 2007; Pötz and Bleuzé 2016; Peek 2015; Huntjens 2019). These metropolitan challenges are often interrelated and will have to be approached from a complex system perspective (see Sect. 4.6). It will require new forms of urban governance, management, and planning that are able to deal with complexity and uncertainty (see Sect. 4.7). There is no 'one-size-fits-all' recipe. These challenges are particularly complex because of the multitude of actors involved in the process. Actors such as urban planners, environmental lawyers, spatial planners, water boards, energy experts, green space managers, urban farmers, citizens, and businesses will have to work together on the technological, legal, financial, and administrative aspects of this sustainability transition. All of whom have their own interests and often divergent perspectives and problems and solutions, complicated by the often sector-specific distribution of financial budgets, and the fact that existing laws and legislation in many instances provide insufficient scope for climate-proof or circular solutions. In the Netherlands, for example, central government is increasingly transferring responsibility for the sustainability transition to municipalities, 
companies, local organizations, and citizens. While decentralization and innovative planning processes with intensive participation are considered necessary for urban governance, it is often a new and overwhelming challenge for these parties to jointly, efficiently, and effectively transform the city into a future-proof living environment.

Research by Prendeville et al. (2018) and Fratini et al. (2019) highlight various shortcomings in the governance of urban sustainability transitions in European cities:

- 'limited attention for understanding and redirecting existing consumption patterns;

- lack of attention for methods of participatory processes for co-production of urban circularity, and little emphasis is given to the inclusion of citizens and communities;

- too much emphasis is given to major incumbent actors, in particular to the role of business and smart, digital, and data-driven technologies' (cf. Fratini et al. 2019).

To make the urban sustainability transition a success, there is a need for new, efficient, and inclusive forms of urban governance, organization, and cooperation between different urban actors and for new decision support and knowledge management tools to support such collaborations. Within this context, making sustainability and the feasibility of possible interventions measurable, or at least create more insight on costs, benefits, risks, and potential trade-offs, helps the parties involved to make better decisions.

In below section I will highlight several examples of applied research activities, where our university together with partners is working on systemic solutions for complex urban sustainability challenges.

\subsection{Climate-Resilient and Healthy Cities}

'Cities are experiencing multiple impacts from global environmental change, and the degree to which they will need to cope with and adapt to these challenges will continue to increase' (cf. Elmqvist et al. 2019). 'A resilient city provides access to healthy food, clean water and air, safe transportation infrastructure, healthy buildings, and health services for all citizens' (cf. Newman et al. 2017). 'The integration of grey, green, and blue infrastructure in urban planning through institutional innovation and structural reorganization of knowledge-action systems may result in large health improvements and increase urban resilience' (cf. Elmqvist et al. 2019).

For instance, cities in Europe, the USA, India, China, Australia, and several other countries are using the concept of a sponge city to design climate-resilient and healthy cities. 'The idea of a sponge city is simple — rather than using concrete to channel away rainwater, you work with nature to absorb, clean, and use the water. Examples include eco-friendly terraces that are used during the dry season as a park for residents to enjoy, while it provides retention capacity during heavy rains, which reduces flooding in cities and prevents disasters and their subsequent costs. It protects the city with less reliance on grey infrastructure like flood walls, dykes, or drainage systems. Not only does this safeguard the city by working with nature, but 
the water is clean, vegetation can grow, and a habitat is created for improving biodiversity. The abundant vegetation found in urban wetlands acts as a filter for domestic and industrial waste and this contributes to improving water quality. Other measures include green walls and roofs, permeable pavements, and green buildings' (cf. Myers 2019).

An example in the Netherlands is 'The Most Sustainable Square Kilometre', which is an area surrounding Leiden Central Station in the midst of a sustainable transformation into the most sustainable kilometre in the Netherlands by 2025. To realize this ambition, 29 organizations, including governments, residents, the private sector, and knowledge institutes, have signed a Green Deal in 2018. A recurrent governance question is how such a cooperation processes can be organized. This requires a better understanding of policy and strategic decision-making, processes of trust-building and conflict resolution, group decision-making for effective urban planning, and to ensure accountability and legitimacy that guarantees balances of interests and perspectives. The transition to climate-resilient and healthy cities will raise normative questions on what makes cities climate-proof and healthy and who should bear the costs involved in the process (Eriksen et al. 2015). Within this context, the integration of important bottom-up processes of learning and knowledge development with top-down policies and strategies is an important challenge.

\subsection{Feeding and Greening Megacities}

'Urbanization will drive intensified consumer demand and value chain concentration, while the distance between food producers and food consumers will continue to widen' (cf. NewForesight and Commonland 2017). Since $80 \%$ of food will be consumed in cities by 2050 , cities can significantly influence the way food is grown, particularly by interacting with producers in their peri-urban and rural surroundings (Ellen MacArthur Foundation 2019). However, current global and regional food systems do not consist of closed cycles, in particular related to $\mathrm{CO}_{2}$, minerals, organic matter, water, and energy. This means that precious building blocks are thrown away. This can lead to scarcity (for example, phosphate), but also to environmental impact (for example, nitrogen and $\mathrm{CO}_{2}$ ). 'By valorizing and/or reusing residual flows and minimizing losses, it is possible to contribute to a food supply that has less impact on the environment. Though much of the foodprint is embodied within imported foodstuffs, cities can still implement design and policy interventions, such as improved nutrient recycling and food waste avoidance, to redress the foodprint' (cf. Goldstein et al. 2017). 'A city's foodprint can rise or fall based on several factors, including the kind of food eaten (grain-fed versus grass-fed meat, meat versus vegetables, water-intensive versus less thirsty crops, etc.), the amount of food wastage, the distance food travels to the city, and other factors' (cf. Gardner et al. 2016).

A potential major contributor to progress in feeding global megacities involves reevaluating regional food systems so that each is much more efficient and selfsustaining than in the current global supply chain (see example of the South Holland 
Food Family in Sect. 6.6). One major advantage is that food production will be closer to the people eating it, resulting in a lower carbon footprint since there will not be long, and often global, cycles of logistics. However, transport is just one factor in the total carbon count of food, while the carbon footprint is only one metric of sustainability, besides social, economic, and other environmental dimensions (Morgan 2009). Therefore, the sustainability of local food systems needs to be measured across multiple dimensions. For example, one important advantage of local food systems is a smaller divide between farmers, consumers, and nature (Sect. 6.4). Hydroponic systems and vertical farming in urban areas also get a lot of attention, although the extent to which they can feed megacities is yet unclear, and these can only be partial solutions for high-yields and ability to supply vast dietary needs of city residents. Section 7.3 will address the potential of circular and regenerative cities as an important development for feeding and greening megacities.

\subsection{From Linear to Circular and Regenerative Cities}

Circular Economy and Regenerative Economy are major themes in urban development, with the aim to be smarter and more efficient with energy, resources, and waste in order to prevent further depletion of raw materials and growing landfills (Kirchherr et al. 2017). "The concept of 'regenerative cities' is seeking to address the relationship between cities and their hinterland, and beyond that with the more distant territories that supply them with water, food, timber, and other vital resources" (cf. Girardet 2017).

Cities today are huge consumers of resources in the purest style of linear economy: make, use, and disposal of resources. As a counter-proposal, is it possible to create future cities that regenerate as many resources as they consume? In any case, 'circular flows of materials in cities promise job creation, operational savings, less waste, and lower carbon emissions' (cf. C40 Cities 2018). Even more so, in a regenerative city, all organic waste is reused, all other materials are separated, recycled, or upcycled, while for some cities all energy needs to come from the sun and wind (e.g. Adelaide), while other cities rely more on hydropower (e.g. Basel). According to UN-Habitat (2020), 'a regenerative city would benefit the environment and the natural ecosystems, driving local economy, and improving the connection and cultural life of its neighbourhoods. Such a city would guarantee its capability for a constant and automatic renovation becoming a vector of prosperity and an essential tool to attain the Sustainable Development Goals (SDG) and to combat climate change' (cf. UN-Habitat 2020; Schmitt et al. 2019).

Does that sound utopian? On the contrary, many inspiring examples of cities in transition to circular and regenerative cities, with a vision to become an 'Eco-City' or 'Ecopolis', can be found around the world (see below examples of Tianjin, Adelaide, and München).

- Tianjin Eco-City in China: This Eco-City, expected to be completed in 2020, will make use of the latest sustainable technologies such as solar power, wind 
power, rainwater recycling, and wastewater treatment/desalination of sea water. In order to reduce the city's carbon emissions, residents will be encouraged to use an advanced light rail system, and China has also pledged that $90 \%$ of traffic within the city will be public transport. The city includes varied eco-landscapes ranging from a sun-powered solarscape to a greenery-clad earthscape for its estimated 350,000 residents to enjoy. In addition to these typical sustainability goals, social harmony is promised to be a key feature of this Eco-city, for example, through subsidized public housing for lower and lower-middle income groups.

- Adelaide in Australia has started with an ambitious plan 15 years ago to become a circular and regenerative city. The city of 1.5 million inhabitants now runs for $45 \%$ on wind and solar energy; storage takes place in a 100 megawatt battery; $\mathrm{CO}_{2}$ emissions have fallen by $15 \%$ since 2000; all organic waste is composted and reused by farmers north of the city; a large-scale reforestation programme ensures air purification; thousands of new green jobs have been created; local democracy is nourished, administrators have a long-term vision again.

- München (Germany): 'The municipal utility company (Stadtwerke München) aims to supply every customer with renewable energy by 2025, reduce $\mathrm{CO}_{2}$ emissions by $50 \%$ by 2030 , and become the first German city to have District Heating that relies solely on renewable sources by 2040' (cf. Ecopolis 2020).

In the Netherlands, the national government has decided that the Netherlands should be circular by 2050 . The energy transition is currently in full swing and topics such as healthy cities, fighting social inequality, and strengthening cohesion in culturally diverse neighbourhoods have enjoyed a steady rise in popularity, as well as new ways to do business, such as social entrepreneurship. Municipalities are looking for new ways to embrace and respond to initiatives by citizens and businesses aimed at sustainable development. Water boards in the Netherlands, for instance, are working on producing energy and raw materials from wastewater, transforming waste and water treatment systems into energy and resource plants. In general, green-blue grids are considered one of the structural building blocks of circular cities, as well as natural ways for closing urban loops (Pötz and Bleuzé 2016). In general, making cities greener and bluer contributes to climate adaptation (see Sect. 7.2), improved biodiversity, improved air quality, energy production from surface water, wastewater, and biomass, recovery of raw materials, such as phosphate and nitrogen from wastewater, boosts quality of life and health, space for recreation and slow traffic, and provides scope for stakeholder participation and citizen engagement (ibid.).

But how does urban planning and governance towards an Eco-City or Ecopolis work in practice, and what urban governance arrangements are required to catalyse a transition from a linear economy to a circular and regenerative economy? C40, a network of the world's megacities committed to addressing climate change, has researched 40 in-depth case studies from cities around the world, demonstrating how municipalities can advance towards zero waste economies (C40 2018). An important finding is that city municipalities need to break away from the traditional 
configuration of government ministries and administrations working in silos (and with sectoral budgets), and to develop common and integrated work programmes and budgets. It requires integrated area development that connects a number of sustainability and social challenges from a systemic perspective. In addition, multi-stakeholder governance and approaches to balance top-down policies and visions with important bottom-up stakeholder processes are considered as one of the most important challenges for translating circular economy principles (see Table 7.1) into urban planning and governance.

One of the major findings of the Future Cities-report (UN-Habitat 2020) is that future cities need citizen-centred governance, where the inhabitant will change from being the subject of observation to become an active partner in the governance of the city. Urban planning and design could be reorganized in such a way that more problems can be solved at the community level (the subsidiarity principle), with stronger citizen engagement and by new coalitions in horizontal innovation networks (see Sect. 3.7). 'Also smart city technology will enable the individual citizen and community of citizens to plan, build, and govern more sustainable, resilient, and regenerative cities' (cf. UN-habitat 2020). In any case, a regenerative city requires a strong sense of community and respect towards their fellow citizens and towards the environment (UN-habitat 2020), which closely resembles the contours of a Natural Social Contract (Sect. 3.7).

The transition to a circular and regenerative city will take place in different sectors (e.g. construction and buildings, agri-food, packaging, electronics, etc.), and at different geographical scales on which cycles can be closed (i.e. local, regional, or international), but will also depend on issues related to ownership, user rights, and multiple value creation. New forms of value creation and inter-organizational circular business models are needed for closing the loop of a product life cycle, and it is unavoidable that questions will arise on whether business capital should be private property or property of the community or a business collective, and how this could be (re-)organized (see Sect. 4.4). 'There is a growing number of urban commons showing that it is not only possible but highly attractive to create commons through which citizens can actively participate in the circular design of their food system, housing or city spaces and the programmes and policies that govern them' (cf. Bollier and Helfrich 2015). 'Several governance benefits are associated with urban green commons such as cost reduction for the management of urban green spaces, as well as designs for reconnecting citizens with nature. Urban green commons play a key role in transforming cities toward more socially and ecologically benign environments' (cf. Colding et al. 2013).

\subsection{Collaboration for the City of the Future}

The present societal challenges require a transition to more transdisciplinary collaboration between professionals with different backgrounds and perspectives. The future professional will be confronted with this transition. Currently, though, degree programmes tend to be highly specific, tailored to individual fields such as landscape 
Table 7.1 Key principles of circular economy from a business perspective (based on BSI 2017 and cf. Brad 2018)

\begin{tabular}{l|l}
\hline CE principle & Explanation \\
\hline $\begin{array}{l}\text { System thinking: understand how your } \\
\text { business impacts the whole ecosystem }\end{array}$ & Companies must consider a holistic approach \\
& in product design and manufacturing to \\
understand how individual decisions and \\
activities affect the wider ecosystem, including \\
natural environment, social and economic \\
dimensions.
\end{tabular}

Innovation: manage resources for more value creation
Companies must innovate in a way that creates business value through the sustainable management of resources incorporated within products and services they design. In other words, this principle strives for connecting economic and environmental gains in product design, manufacturing, and use. It requires business models where companies sell solutions not products, and owning is replaced by sharing.

Stewardship: take responsibility for the ripple-effect impacts that come up from your business activities

Companies have to manage the direct and indirect impacts of their decisions and activities across the systems they create and interact with. Stewardship means a company is responsible for any consequence of its managerial decisions in relation to product design, its production and exploitation, as well as its end-of-life.

Collaboration: secure benefits at system wide level by strong cooperation in the value chain

\section{Companies have to conduct continuous} cooperation, both internally and with external stakeholders, through various business arrangements such as to create mutual business value for all stakeholders.
Value optimization: keep materials at the highest value and function quality

Companies have to keep all products, components, and materials at their highest value and utility at all times, such as recirculation to be done with minimal energy consumption. Recirculation, in any form, is not the goal of circular economy. Recirculation is only a mean to create new value in the system from elements that are considered loss or waste. Value added is in cost saving, in lower environmental impact, in higher business resilience, in new revenue streams, and in better relationship with customers.

Transparency: reveal to everyone the environmental impact of all your business activities.
Companies are fully aware and open about decisions and activities that affect their ability to move towards a more sustainable and circular mode of operation and are willing to communicate their effects in a clear, accurate, timely, honest, and complete manner. 
architecture, economics, healthcare, social work, urban planning or technology. Our challenge is to prepare these students for their future and to educate them to think across sectoral boundaries and to work transdisciplinary, thereby addressing the grand societal challenges such as climate adaptation, circularity, urban health, citizen participation, and the energy transition. We aim to achieve this by creating an intersectoral transdisciplinary minor, called 'Collaboration for the City of the Future', with support of the Comenius Leadership Fellow Programme of the Netherlands Organisation for Scientific Research (NWO).

This Minor creates a learning environment that will serve as a Living Lab (see Sect. 4.10) where we will structurally examine and discover the applicability of transdisciplinary collaboration in education for all programmes at Inholland University and higher professional education as a whole. This Minor will bring together students from various educational backgrounds, such as social work, landscaping, economics, technology, and urban planning. We will teach the students the process skills needed to work in transdisciplinary teams. As a result, they learn to work together across multiple disciplines, united by an over-arching vision for a sustainable, healthy and inclusive city of the future.

Open Access This chapter is licensed under the terms of the Creative Commons Attribution 4.0 International License (http://creativecommons.org/licenses/by/4.0/), which permits use, sharing, adaptation, distribution and reproduction in any medium or format, as long as you give appropriate credit to the original author(s) and the source, provide a link to the Creative Commons license and indicate if changes were made.

The images or other third party material in this chapter are included in the chapter's Creative Commons license, unless indicated otherwise in a credit line to the material. If material is not included in the chapter's Creative Commons license and your intended use is not permitted by statutory regulation or exceeds the permitted use, you will need to obtain permission directly from the copyright holder.

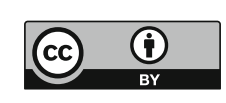

